\title{
Assessing the potential impact of vaccination programs on invasive pneumococcal disease: Data from
}

\section{population-based surveillance}

\begin{abstract}
Allison McGeer MD FRCPC ${ }^{1}$, Karen Green RN CIC ${ }^{1}$, Lisa Landry BSc ${ }^{1}$, James Talbot MD PhD ${ }^{2}$, Ellie Goldenberg MSc ${ }^{1}$, The Toronto Invasive Bacterial Diseases Network*
\end{abstract}

$\mathrm{I}$ nfections due to Streptococcus pneumoniae remain a major cause of morbidity, mortality and health care expenditure around the world. The recent emergence of antibiotic resistance in $S$ pneumoniae and the development of conjugate pneumococcal vaccines have highlighted the need to better understand the epidemiology of this disease so that preventive measures can be appropriately targeted.

Pneumococcal infections are not reportable in Canada. While a number of publications have now documented the increase in antibiotic resistance in $S$ pneumoniae, there are no published reports describing the epidemiology of invasive infection. To better understand the epidemiology of infection in
Canada, the Toronto Invasive Bacterial Diseases Network (TIBDN) has been performing population-based surveillance for invasive pneumococcal disease in Metropolitan Toronto and the regional municipality of Peel in Ontario since 1995.

TIBDN is a collaborative network of all hospitals and the three largest private clinical microbiology laboratories serving the population of Metropolitan Toronto and Peel Region (population 3.4 million). Prospective surveillance for all cases of invasive bacterial disease in residents of this geographic area has been conducted since January 1, 1995. Invasive pneumococcal disease is defined as any infection associated with $S$ pneumoniae isolated from a sterile site. Sterile site iso-

\footnotetext{
*Members of the Toronto Invasive Bacterial Diseases Network: RM Bannatyne, St Michael's Hospital; I Campbell, The Toronto Hospital; P Da Camara, Toronto East General Hospital; R Devlin and H Dick, Wellesley-Central Hospital, Toronto; IN Gaid, Ajax \& Pickering General Hospital, Ajax; P Garrod, Oakville Trafalgar General Hospital, Oakville; A Geldbloom, Scarborough General Hospital, Scarborough; A Gryfe, The Trillum Health Centre, Toronto; F Jamieson, Ontario Public Health Laboratory, Toronto; J Henning, Credit Valley Hospital, Mississauga; M Krajden, The Toronto Hospital; S Krajden, St Joseph's Health Centre, Toronto; KS Lee, Humber River Regional Hospital, Toronto; M Loeb, Hamilton Health Sciences Corporation, Hamilton, Ontario; M Lovgren, National Centre for Streptococcus, Edmonton, Alberta; DE Low, Mount Sinai Hospital; AG Matlow, The Hospital for Sick Children; B Mederski, North York General Hospital, Toronto; Z Moloo, Peel Memorial Hospital, Mississauga; M Naus, Ontario Ministry of Health, Toronto; D Noria, Scarborough Grace Hospital, Scarborough; P O'Brien, Etobicoke General Hospital; B Oliver, Humber River Regional Hospital; K Ostrowska, The Trillum Health Centre, Toronto; JL Platt, Centenary Health Centre, Scarborough, Ontario; A Schuchat, Centers for Disease Control and Prevention, Atlanta, Georgia; P Shokry, Markham Stouffille Hospital, Markham; AE Simor, Sunnybrook Health Science Centre, Toronto; F Smaill, Chedoke McMaster Hospital, Hamilton; D Sturman, Riverdale Hospital; E Szentgyorgi, North York Branson Hospital; M Tischler, Wellesley-Central Hospital; P Van Nostrand, The Toronto Rehabilitation Institute; $M$ Vearncombe, Women's College Hospital; $S$ Walmsley, The Toronto Hospital, Toronto, Ontario

${ }^{1}$ Mount Sinai Hospital, Toronto, Ontario; ${ }^{2}$ National Centre for Streptococcus, Edmonton, Alberta

Correspondence: Dr Allison J McGeer, Mount Sinai Hospital, 600 University Avenue, Toronto, Ontario M5G 1 X5. Telephone 416-586-3118, fax 416-586-3140, e-mail amcgeer@mtsinai.on.ca
} 


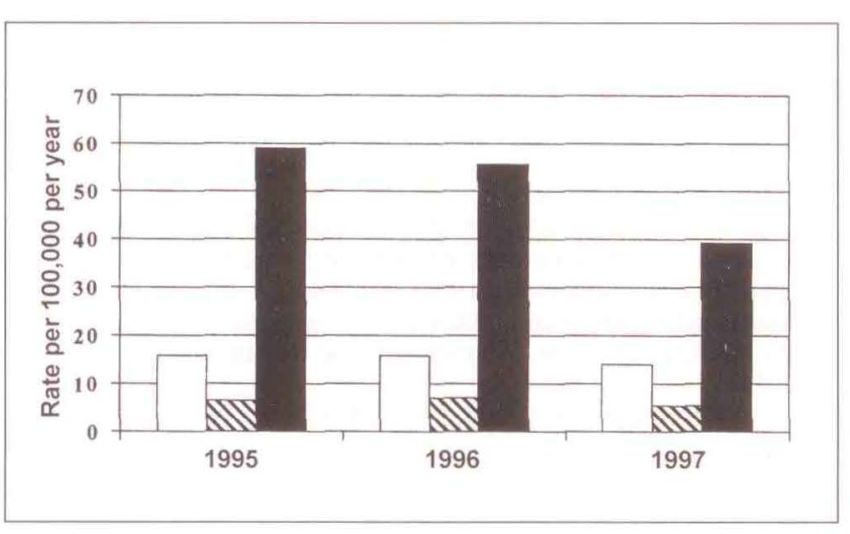

Figure 1) Annual incidence of invasive pneumococcal disease in Metropolitan Toronto and Peel Region. Open bars represent rates in children (younger than 16 years of age), hatched bars younger adults (16 to 64 years of age) and closed bars older adults (65 years of age or older)

lates are reported by telephone to the central study office at the Mount Sinai Hospital, Toronto, Ontario. Clinical data are collected from the patient's physicians and/or the hospital's infection control practitioner. For 1995, case isolates were shipped to the central laboratory, where they were confirmed as $S$ pneumoniae, and antimicrobial susceptibility testing was performed to National Committee for Clinical Laboratory Standards (NCCLS) standards by microbroth dilution (1). Capsular typing of isolates was performed at the National Centre for Streptococcus in Edmonton, Alberta.

The overall incidence of disease was 14.4 per 100,000 population in $1995,16.1$ per 100,000 in 1996 and 11.8 per 100,000 in 1997. Rates of disease were markedly higher in the elderly, and most of the decrease in incidence from 1995 to 1997 was in this age group (Figure 1).

For the 470 cases of invasive pneumococcal disease that were identified in 1995, complete clinical information was available for $97 \%$ ( 455 of 470 ) of cases. The most common clinical diagnoses were pneumonia (300 infections, 66\%), bacteremia without focus ( 75 infections, $17 \%$ ), meningitis (14 infections, $3 \%$ ) and otitis media (13 infections, 3\%). The overall case fatality rate was $18.6 \%$. Case fatality varied with the age of the patient; only $2.2 \%$ of children died compared with $28 \%$ of those age 65 years and older. Thirty-two episodes of disease $(7 \%)$ were nosocomial, and $44(10 \%)$ occurred in residents of other institutions ( 37 in nursing homes, three in retirement homes, and two each in jails and psychiatric facilities). There were no detected outbreaks in any institutions.

The serotypes most commonly associated with disease were 14 (23\% of cases), 4 (9.7\%), 23F (8.8\%), 6B (8.4\%), 3 $(7.5 \%), 9 \mathrm{~V}(7.0 \%)$ and $19 \mathrm{~F}(5.7 \%)$. Overall, $92 \%$ of cases were caused by isolates with serotypes contained in the 23 -valent vaccine, and $66 \%$ by serotypes in the current heptavalent conjugate vaccines. Penicillin resistance was relatively uncommon. In 1995 , only $10.8 \%$ of isolates from children and $6.2 \%$ of isolates from adults were penicillin nonsusceptible; in 1997, this percentage increased to $12.4 \%$ in children and $12.7 \%$ in adults.

Underlying medical conditions that might predispose patients to invasive pneumococcal disease were present in 18
TABLE 1

Risk of invasive pneumococcal disease in adults associated with selected underlying conditions, metropolitan Toronto/Peel Region, 1995

\begin{tabular}{|c|c|c|c|c|}
\hline $\begin{array}{l}\text { Underlying } \\
\text { condition }\end{array}$ & $\begin{array}{c}\text { Cases } \\
(\%) \\
n=357\end{array}$ & $\begin{array}{c}\text { Annual } \\
\text { incidence } \\
\text { (per 100,000) }\end{array}$ & $\begin{array}{l}\text { Relative risk } \\
\qquad(95 \% \mathrm{CI})\end{array}$ & $\mathrm{P}$ \\
\hline Multiple myeloma & $\begin{array}{c}13 \\
(3.6 \%)\end{array}$ & 2900 & $\begin{array}{c}210 \\
(125 \text { to } 370)\end{array}$ & $<0.001$ \\
\hline $\begin{array}{l}\text { Chronic lung disease } \\
\text { (excluding asthma } \\
\text { alone) }\end{array}$ & $\begin{array}{c}82 \\
(23 \%)\end{array}$ & 130 & $\begin{array}{c}12 \\
(9.5 \text { to } 15)\end{array}$ & $<0.001$ \\
\hline Cancer & $\begin{array}{c}68 \\
(19 \%)\end{array}$ & 139 & $\begin{array}{c}11 \\
\text { (8.5 to } 14)\end{array}$ & $<0.001$ \\
\hline HIV & $\begin{array}{c}19 \\
(5.3 \%)\end{array}$ & 126 & $\begin{array}{c}9.3 \\
\text { (5.8 to } 15 \text { ) }\end{array}$ & $<0.001$ \\
\hline Diabetes mellitus & $\begin{array}{c}48 \\
(13 \%)\end{array}$ & 57 & $\begin{array}{c}4.7 \\
\text { (3.5 to } 6.3)\end{array}$ & $<0.001$ \\
\hline Heart disease & $\begin{array}{c}68 \\
(19 \%)\end{array}$ & 86 & $\begin{array}{c}6.0 \\
(4.6 \text { to } 7.9)\end{array}$ & $<0.001$ \\
\hline
\end{tabular}

HIV Human immunodeficiency virus

(20\%) of 91 children and $277(77 \%)$ of 362 adults for whom data were available. The increased risk of disease associated with different chronic illnesses is shown in Table 1. Seventysix per cent of cases occurred in patients eligible for vaccination: $35 \%$ in chronically ill persons 65 years of age and older, $30 \%$ in chronically ill persons under 65 years of age and $11 \%$ in the healthy elderly. The case fatality rate was $5.6 \%$ in young, healthy persons, $14 \%$ in chronically ill persons 65 years of age or younger, $15 \%$ in the healthy elderly and $32 \%$ in the chronically ill elderly. Overall, $93 \%$ of deaths occurred in vaccineeligible patients.

Twenty-five of $247(10 \%)$ eligible patients for whom adequate vaccination histories could be obtained had received pneumococcal vaccine before their episode of illness: 13 were young, chronically ill adults (six with human immunodeficiency virus infection), eight were over 65 years of age and had at least one chronic underlying illness, and four were over 65 years of age with no underlying illness. All four older persons without underlying illness and six of eight with chronic illnesses were nursing home residents. An additional 11 of $269(4 \%)$ vaccine-eligible and surviving patients were vaccinated after their episode of illness.

\section{CONCLUSIONS}

Rates of pneumococcal disease in this area are similar to those in published reports from the United States and northern Europe (2-4), and to that found by the Canadian Sentinel Health Unit Surveillance System. In 1995, the majority of cases and virtually all deaths occurred in vaccine-eligible patients as defined by the National Advisory Committee on Immunization $(5,6)$. Vaccine use up until 1995 was suboptimal. The decrease in rates of disease among the elderly between 1995 and 1997 may reflect increased use of vaccine associated with the Ontario pneumococcal vaccination program. However, $25 \%$ of all invasive disease occurs in persons not eligible for vaccination, and another $30 \%$ occurred in persons with 
immunocompromising medical illnesses for which vaccine efficacy would be expected to be low (6). Thus, even a pneumococcal vaccination program that is effective and cost effective (7) may only reduce overall rates of invasive pneumococcal disease by $15 \%$ to $25 \%$. If surveillance is to be used to evaluate the success of pneumococcal vaccination programs, it will be necessary both to measure changes in the incidence of disease in specific at risk subgroups and to know vaccination rates in these subgroups.

\section{REFERENCES}

1. National Committee for Clinical Laboratory Standards.

Performance Standards for Antimicrobial Susceptibility Testing; Eighth Informational Supplement [NCCLS document M100-S8]. Villanova: NCCLS, 1998.
2. Hedlund J, Svenson SB, Kalin M, et al. Incidence, capsular types and antibiotic susceptibility of invasive Streptococcus pneumoniae in Sweden. Clin Infect Dis 1995;21:948-53.

3. Hoffman J, Cetron MS, Farley MM, et al. The prevalence of drug-resistant Streptococcus pneumoniae in Atlanta. N Engl J Med 1995:333:481-6.

4. Raz R, Elhanan G, Shimoni Z. Pneumococcal bacteremia in hospitalized Israeli adults: epidemiology and resistance to penicillin. Clin Infect Dis 1997;24:1164-8.

5. National Advisory Committee on Immunization. Canadian Immunization Guide, 5th edn. Ottawa: Health Canada, 1998.

6. Fine MI, Smith MA, Carson CA, et al. Efficacy of pneumococcal vaccination in adults. A meta-analysis of randomized controlled trials. Arch Intern Med 1994:154:2666-77.

7. Sisk JE, Moskowitz AJ, Whang W, et al. Cost-effectiveness of vaccination against pneumococcal bacteremia among elderly people. JAMA 1997;278:1333-9. 


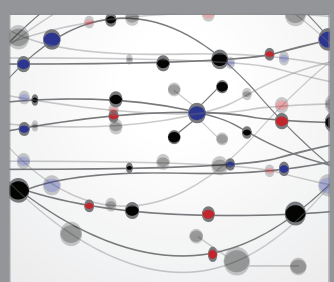

The Scientific World Journal
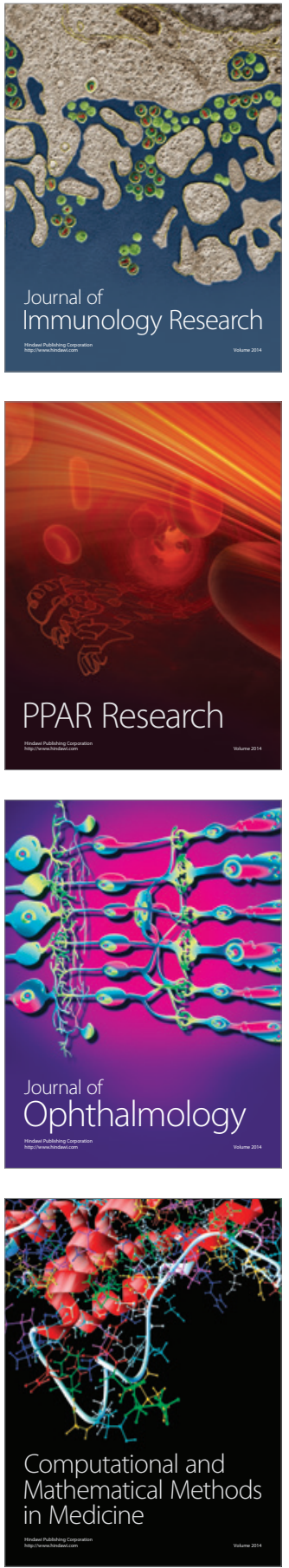

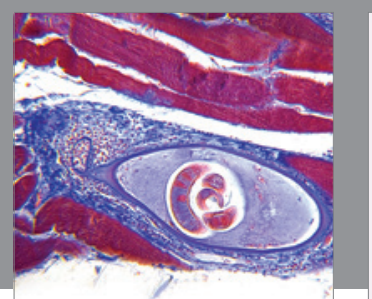

Gastroenterology Research and Practice

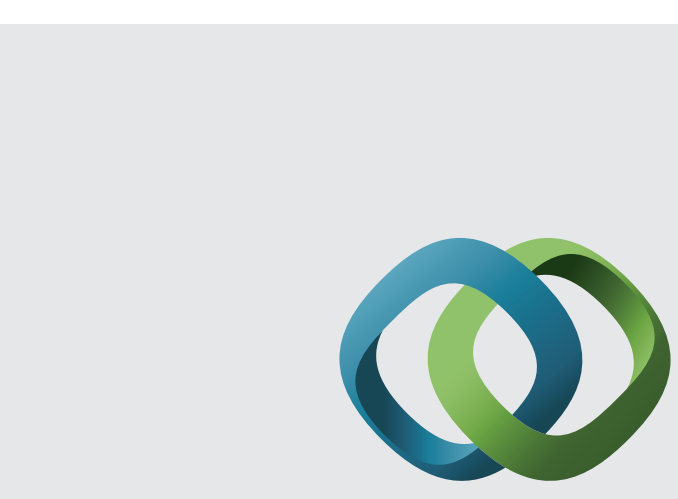

\section{Hindawi}

Submit your manuscripts at

http://www.hindawi.com
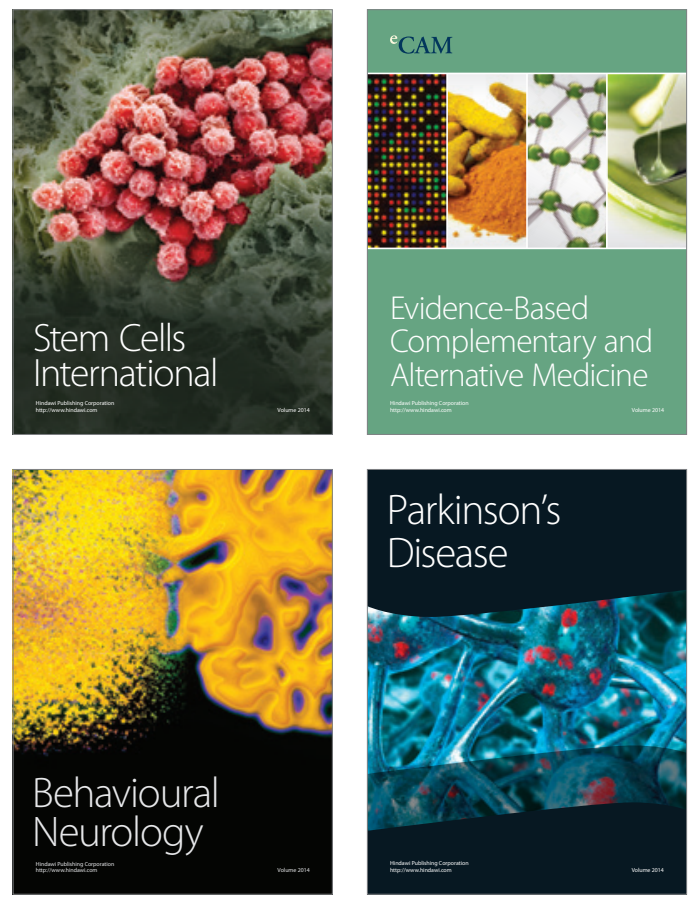
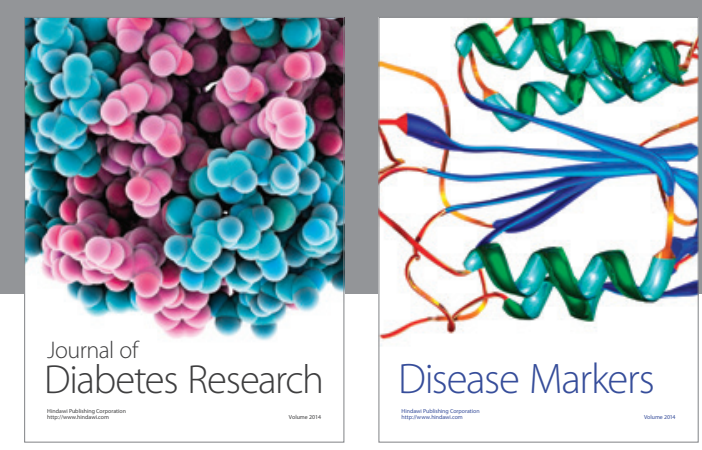

Disease Markers
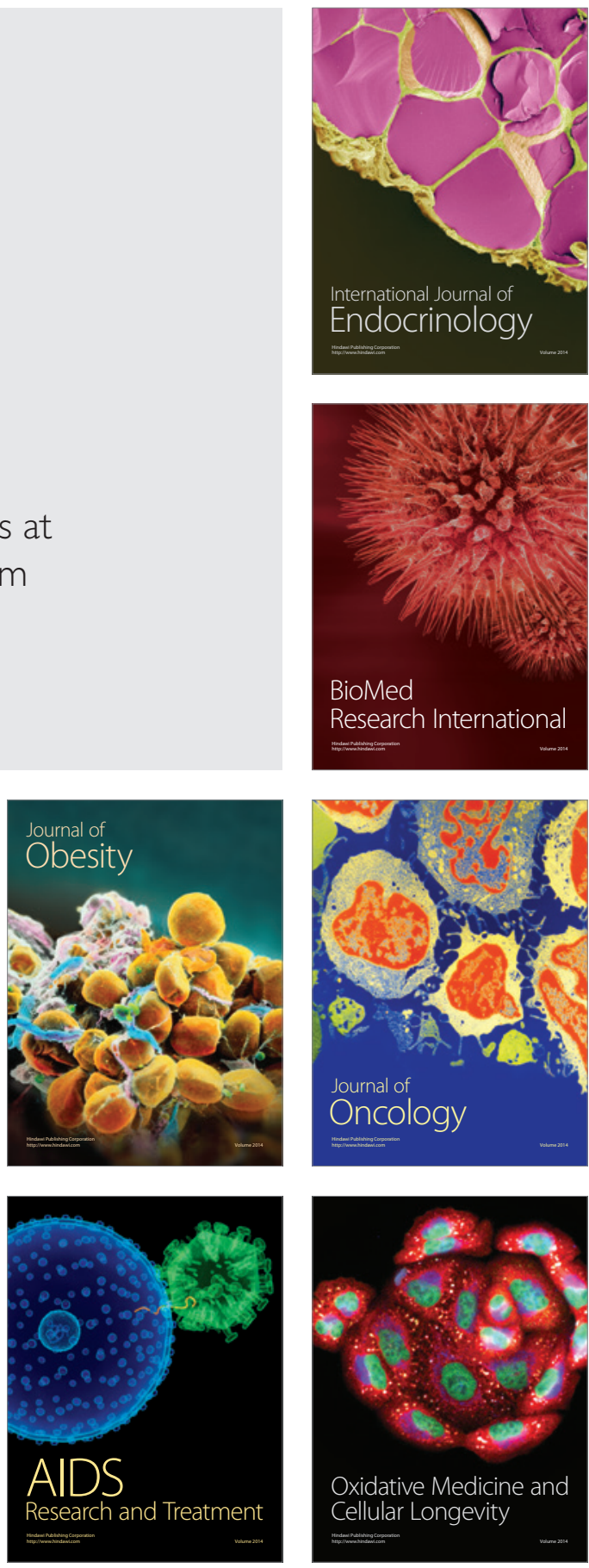